\title{
Band-Notched UWB Antenna with Switchable and Tunable Performance
}

\author{
Wei Wu, Yun-Bo Li, Rui-Yuan Wu, Chuan-Bo Shi, and Tie-Jun Cui \\ School of Information Science and Engineering, Southeast University, Nanjing 210096, China \\ Correspondence should be addressed to Tie-Jun Cui; tjcui@seu.edu.cn
}

Received 21 April 2016; Revised 19 June 2016; Accepted 23 June 2016

Academic Editor: Renato Cicchetti

Copyright (C) 2016 Wei Wu et al. This is an open access article distributed under the Creative Commons Attribution License, which permits unrestricted use, distribution, and reproduction in any medium, provided the original work is properly cited.

\begin{abstract}
A band-notched UWB antenna is presented, which can switch between two notch bands and tune the central frequency simultaneously. It is the first time that the switchable and tunable behaviours are combined together in band-notched UWB antennas. In the band-notched structure, PIN diodes are used to switch the lower and upper frequency bands, while varactors could vary the central frequency of each notch band continuously. Measurement results show that the notch bands could switch between $4.2 \mathrm{GHz}$ and $5.8 \mathrm{GHz}$ when the state of varactors is fixed, and the ranges of tuning are $4.2-4.8 \mathrm{GHz}$ and $5.8-6.5 \mathrm{GHz}$ when the state of PIN diodes is ON and OFF, respectively.
\end{abstract}

\section{Introduction}

UWB communication $(3.1-10.6 \mathrm{GHz})$ has attracted much attention in recent years owing to its high data rates, great channel capacity, and low power dissipation [1]. As a necessary component in the system, UWB antenna has been widely investigated. There are many shapes of the radiator, such as circle, rectangle, cup, and pyramid [2-5]. Besides, according to the relative position between the radiator and the ground, the UWB antenna could be classified into the coplanar waveguide (CPW) top-radiator-bottom-ground and stereoscopic structure [4-6].

Nevertheless, parts of UWB spectrum would overlap with other communication systems, such as WiMax (3.33.8 GHz), WLAN $(5.15-5.85 \mathrm{GHz})$, or X-band satellite communication links (7.9-8.4 GHz) [7], which would cause electromagnetic interference. Generally, there are two ways to produce notch bands. One is adding stubs beside the feeding line or ground to produce notch bands [8-10], while the other is making slits in the feeding line or radiator [11, 12]. Of course, the combination of these two methods could produce multiple notch bands.

Afterwards, under the tendency of self-adaptive technologies and smart antennas, the concept of reconfiguration has been introduced into antennas, where PIN diodes and varactors are common means to realize smart functions. As a specific term, the UWB antenna with reconfigurable notch bands has been observed recently. In general, these designs could be classified into two categories according to the function. One is to produce switchable notch bands with PIN diodes $[7,13,14]$. In fact, modifying the ON or OFF status of the diodes, the electrical path length of the surface currents changes and consequently the resonant processes responsible for the formation of the notch bands. Another category is using varactors to produce continuously changeable notch bands, so-called tunable notch bands $[15,16]$. The capacitance of varactor varies continuously when the reverse bias voltage changes, leading to the resonance moving on the frequency spectrum. PIN diodes or varactors applied with stubs and slits could produce various band-notched UWB antennas.

In this paper, it is the first time that PIN diodes and varactors are combined together. The notch bands of the UWB antenna are not only switchable but also tunable. In the design, stubs with a pair of PIN diodes and varactors consist of band-notched structure. The ON and OFF states of PIN diodes are controlled by reverse bias voltages of $5 \mathrm{~V}$ and $0 \mathrm{~V}$, which makes two notch bands (the lower and upper) switchable. Once the state of PIN diode is fixed, the continuously varying reverse voltage from $0 \mathrm{~V}$ to $15 \mathrm{~V}$ would make the notch band scannable in a certain range on the spectrum. 


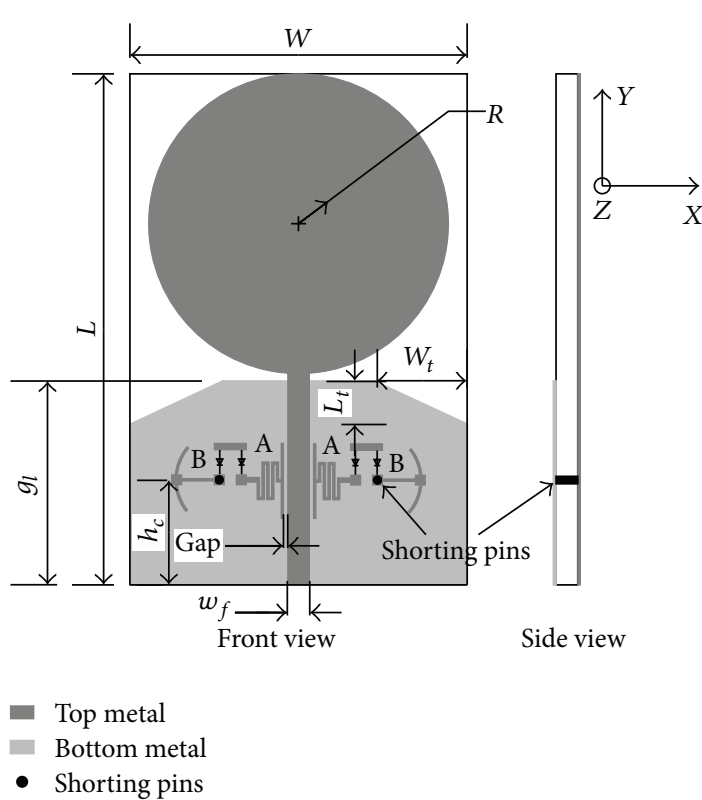

(a)

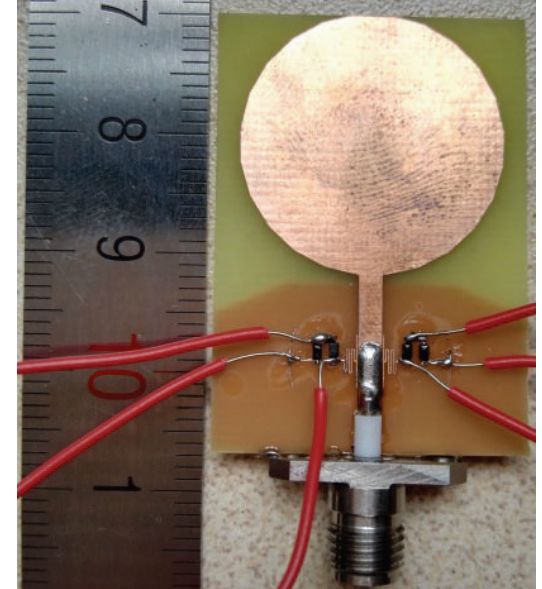

(b)

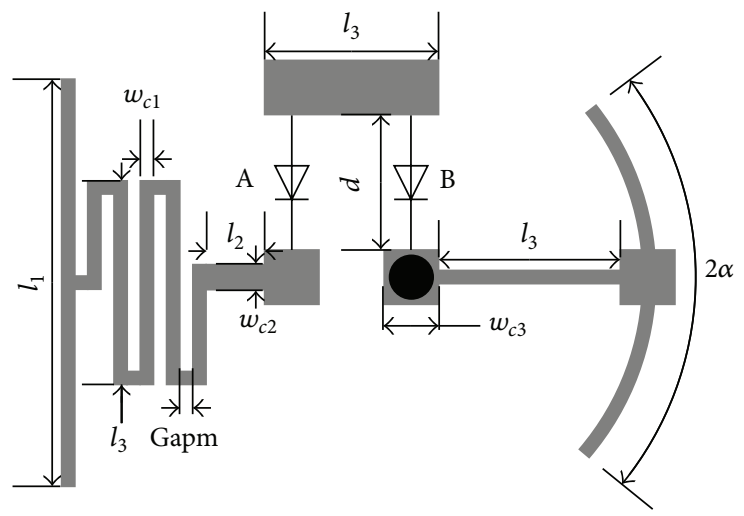

(c)

FIGURE 1: Geometry of the proposed switchable and tunable band-notched UWB antenna: (a) antenna structure, top view (left) and side view (right); (b) photo of fabricated prototype; (c) detailed band-notched structure.

Measurement results show that the notch band could be switched between $4.2 \mathrm{GHz}$ and $5.8 \mathrm{GHz}$ when reverse voltages on varactors are fixed at $0 \mathrm{~V}$, and the tuning ranges are $4.2 \mathrm{GH}-4.8 \mathrm{GHz}$ and $5.8 \mathrm{GH}-6.5 \mathrm{GHz}$ under the $\mathrm{ON}$ and OFF states of PIN diodes.

\section{Antenna Design}

As is illustrated in Figures $1(\mathrm{a})$ and $1(\mathrm{~b})$, the design is fabricated on a $1 \mathrm{~mm}$ thick FR4 $\left(\varepsilon_{r}=4.3 ; \tan \delta=0.002\right)$ substrate, where the dimension is $26 \mathrm{~mm} \times 36.6 \mathrm{~mm}$. On the bottom layer, the ground with two cutting triangles for better impedance matching is printed. The band-notched structure, the feeding line, and the UWB circular monopole antenna are printed on the top layer. Among them, the band-notched structure is located beside the feed line. Detailed antenna parameters are listed in Table 1.
Figure 1(c) shows the detailed band-notched structure. The capital letters A and B appearing in Figure 1(c) refer to PIN diodes and varactors, respectively. In the PIN diodes the current will go through or it will be cut off, when the reverse bias voltage is $5 \mathrm{~V}$ or $0 \mathrm{~V}$, which corresponds to the $\mathrm{ON}$ or OFF state. As for varactors, the capacitance will decrease from $2.37 \mathrm{pF}$ to $0.46 \mathrm{pF}$ when the reverse voltage increases from $0 \mathrm{~V}$ to $15 \mathrm{~V}$. Besides, the meander line has been adopted to reduce the size of the inductance necessary for the excitation of the resonance process, while the shorting pins are used to suppress the high-order notch bands.

\section{Study of the Notch Band Characteristic}

In the design, varactors SMV1231-079LF and PIN diodes SMP1320-079LF which are all from Skyworks Solutions are applied. In the numerical simulation, the varactors and the 
TABLE 1: Optimized parameters of the proposed antenna.

\begin{tabular}{ccccccccccccccccccc}
\hline & $L$ & $W$ & $g_{l}$ & $h_{c}$ & $R$ & $W_{t}$ & $L_{t}$ & gap & $w_{f}$ & $l_{1}$ & $l_{2}$ & $l_{3}$ & $w_{c 1}$ & $w_{c 2}$ & $w_{c 3}$ & gapm & $d$ & $2 \alpha$ \\
\hline Unit $(\mathrm{mm})$ & 36.6 & 26 & 14 & 7.6 & 11 & 6 & 2.6 & 0.1 & 1.9 & 4.4 & 0.5 & 2 & 0.1 & 0.2 & 0.4 & 0.1 & 1.5 & 80 \\
\hline
\end{tabular}

TABLE 2: Effective parameters of the circuits.

\begin{tabular}{lcccc}
\hline Type & Bias voltage $(\mathrm{V})$ & $C(\mathrm{pF})$ & $R(\Omega)$ & $L(\mathrm{nH})$ \\
\hline \multirow{3}{*}{ Varactor } & $\mathbf{0}$ & 2.37 & 1.65 & 0.7 \\
& $\mathbf{8}$ & 0.54 & 0.09 & 0.7 \\
& $\mathbf{1 5}$ & 0.46 & 0.005 & 0.7 \\
\hline \multirow{2}{*}{ PIN diode } & $\mathbf{0}(\mathbf{O F F})$ & 0.25 & 0.8 & 0.427 \\
& $\mathbf{5}(\mathbf{O N})$ & 38.91 & 0.015 & 0.774 \\
\hline
\end{tabular}

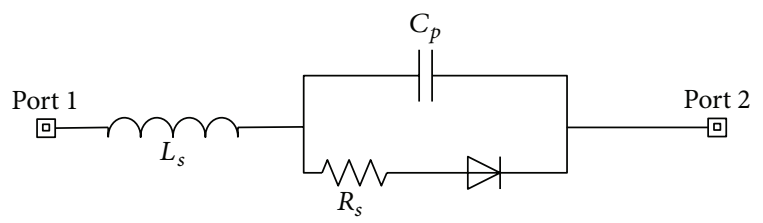

(a)

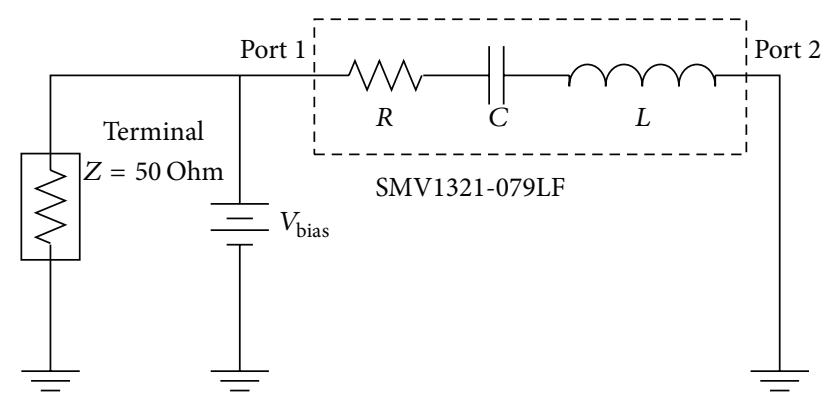

(b)

Figure 2: Extraction of effective parameters of the PIN diode and the varactor: (a) the spice model of the varactor; (b) circuit model of extraction, which is used to extract the effective circuit parameters of the varactor based on its spice model.

PIN diodes have been replaced, within the operating band, by equivalent circuits composed by a series RLC circuit. All the numerical simulations are conducted in HFSS 15 . The exact circuit parameters are listed in Table 2, which are extracted from their spice model by using Advanced Design System 2009, as is shown in Figure 2. In the following simulation, the effective RLC circuits will represent the varactor and the PIN diode for simplicity.

The equivalent circuit of the band-notched structure is shown in Figure 3. The circuit consists of two seriesconnected impedances. One of the impedances $R_{p 1}+j X_{p 1}$ or $R_{p 2}+j X_{p 2}$ describes the effect of the PIN diode in the ON or OFF state, while the other is the variable impedance describing the electric behaviour of the varactor diode under changing reverse bias voltage. Besides, the rest RLC of the circuit produced by other notch band structures are also
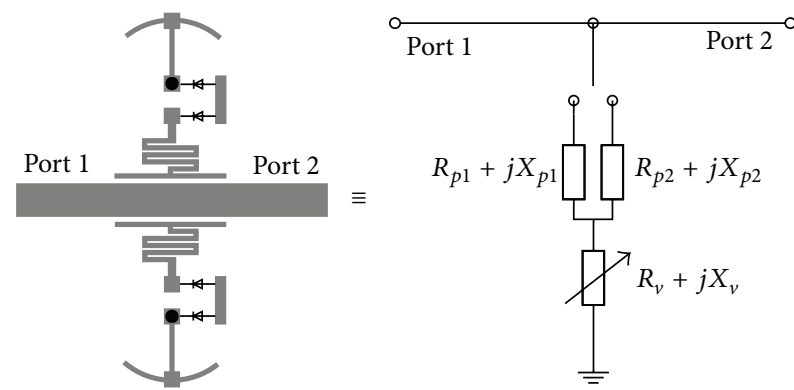

FIGURE 3: Equivalent circuit of the band-notched structure.

added into $R_{v}+j X_{v}$ for simplicity. When the resonance of series circuit happens, signal will not transfer from port 1 to port 2 but will pass through the circuit to the ground, as if port 2 is shorted, and this is the reason that the notch band shows up on the UWB spectrum.

It is clear that the resonant frequency of the notch band will decrease when neither or both of the inductance and capacitance increase in the band-notched structure. Owing to the series connection of the elements forming the bandnotched structure depicted in Figure 3, the PIN diode acts like a switch at which the equivalent capacitance values ranging between $0.25 \mathrm{pF}$ and $38.91 \mathrm{pF}$ are associated, as is shown in Table 2. To put it in another way, in this design, ON state of PIN diodes and $0 \mathrm{~V}$ reverse bias voltage on varactors corresponds to the lowest resonance (series connection of $38.91 \mathrm{pF}$ and $2.37 \mathrm{pF}$ ), while OFF state of PIN diodes and $15 \mathrm{~V}$ reverse bias voltage on varactors represents the highest resonance (series connection of $0.25 \mathrm{pF}$ and $0.46 \mathrm{pF}$ ). That is, the PIN diode determines whether the resonance of notch band is in the lower or upper band, and varactors realize scanning in a range of spectrums once the state of PIN diode is fixed.

\section{Results and Discussion}

Figure 4 shows the distribution of the surface current on the feedline and the band-notched structure when the state of PIN diodes is ON and OFF, while the bias voltage is fixed at $0 \mathrm{~V}$. It can be seen that, at band-notched frequencies, the energy is trapped in the notch band structure rather than passing through the feedline.

As is illustrated in Figure 5, a notch band shows up on the basis of UWB spectrum. The measurement of the reflection coefficient is obtained when PIN diodes work at ON or OFF state, while the reverse voltage on varactors is fixed at $0 \mathrm{~V}$. It is clear that the resonant frequency of notch band is $4.2 \mathrm{GHz}$ when PIN diodes are at ON state, while the central frequency is $5.8 \mathrm{GHz}$ when PIN diodes are at OFF state. When the PIN 


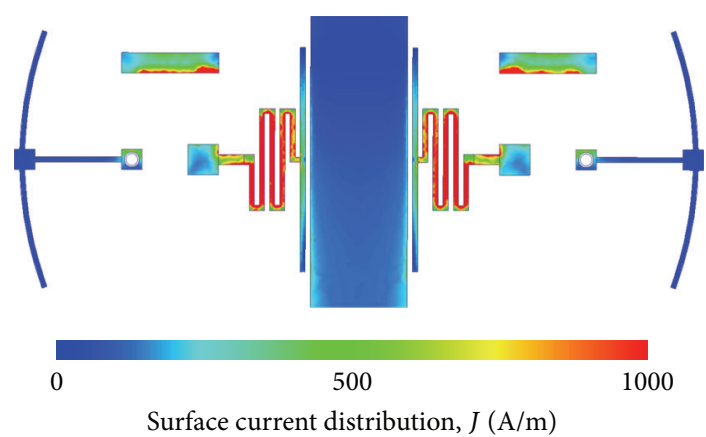

(a)

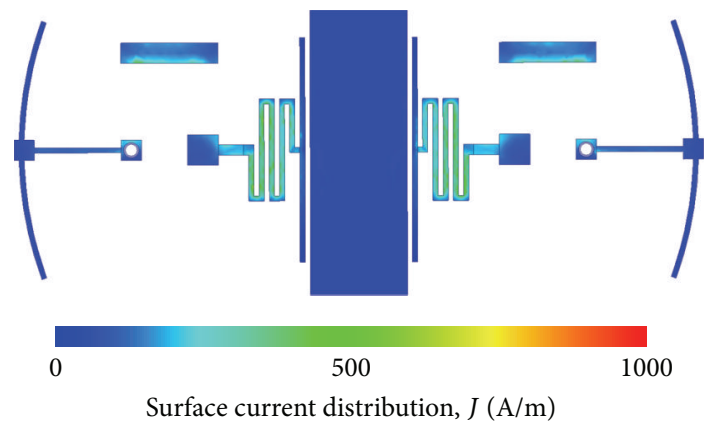

(b)

FIGURE 4: Distribution of the surface current on the feedline and the band-notched structure: (a) at $4.2 \mathrm{GHz}$ when the state of PIN diodes is $\mathrm{ON}$ and bias voltage is $0 \mathrm{~V}$; (b) at $5.8 \mathrm{GHz}$ when the state of PIN diodes is OFF and bias voltage is $0 \mathrm{~V}$.

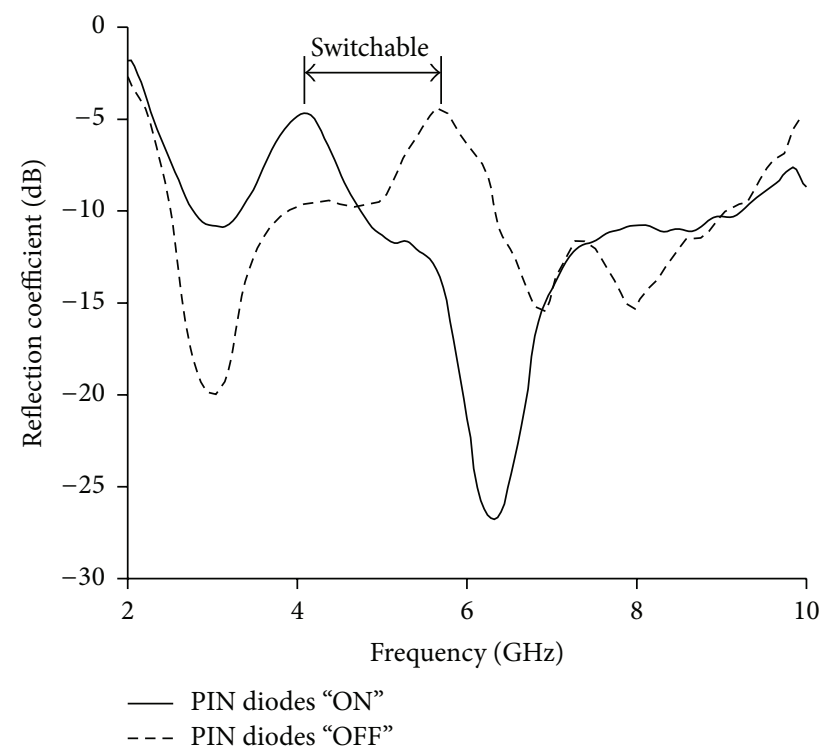

Figure 5: Measured reflection coefficient under ON and OFF states of PIN diode when the reverse voltage on varactors is fixed at $0 \mathrm{~V}$.

diodes are ON, the electric length of resonance is relatively longer, which would lead to a lower resonant frequency.

Once the states of PIN diodes are fixed, the varying reverse voltage on varactors would produce a continuously changeable notch band. As demonstrated in Figure 6, when the bias voltage on varactors changes from $0 \mathrm{~V}$ to $15 \mathrm{~V}$, the

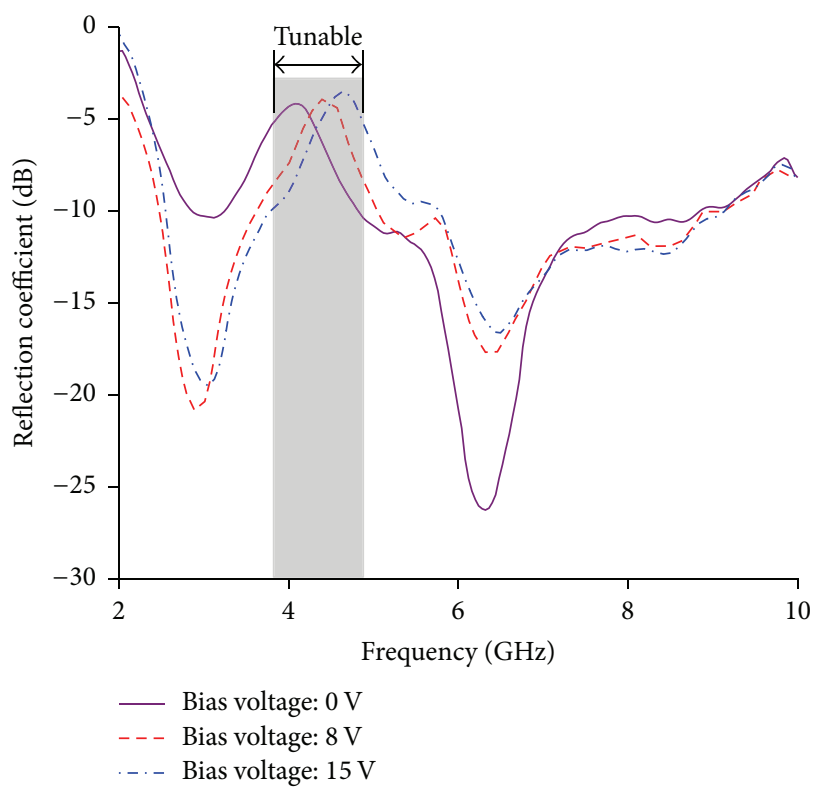

(a)

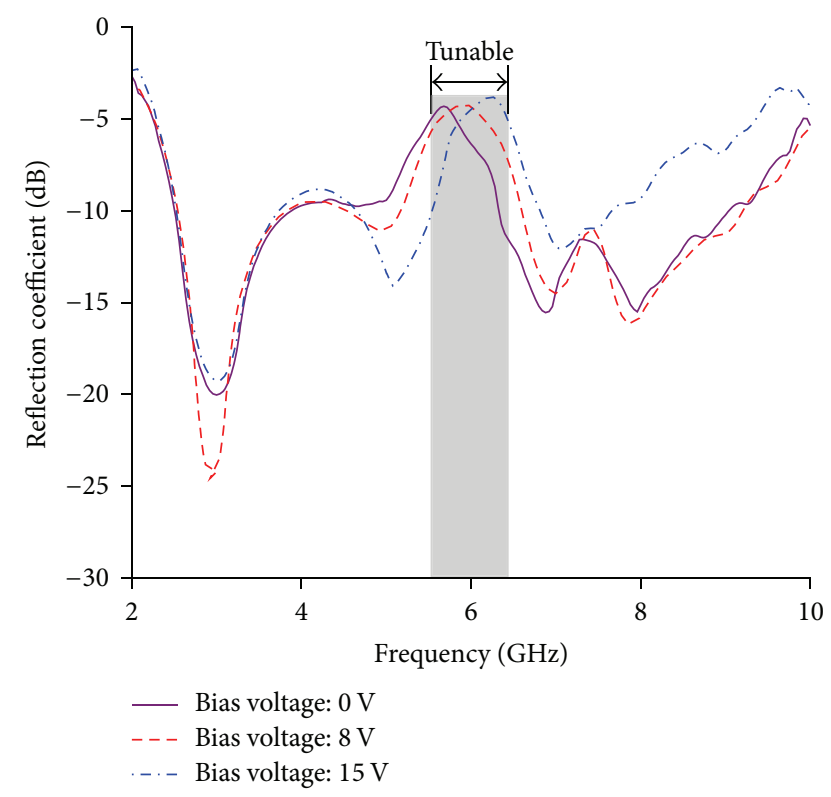

(b)

FIgURE 6: Measured reflection coefficient of the proposed reconfigurable band-notched UWB antenna with the reverse voltage on varactors varying from $0 \mathrm{~V}$ to $15 \mathrm{~V}$ : (a) the state of PIN diodes is ON; (b) the state of PIN diodes is OFF.

central frequency of resonance varies continuously from 4.2 to $4.8 \mathrm{GHz}$ and from 5.8 to $6.5 \mathrm{GHz}$ under $\mathrm{ON}$ and OFF states of PIN diodes, respectively. The reason is that the capacitance of varactors ranges from $2.37 \mathrm{pF}$ to $0.46 \mathrm{pF}$ under $0 \mathrm{~V}-15 \mathrm{~V}$ reverse voltage, which yields the shifting resonance of notch bands.

Figures 5 and 6 together confirm the function of switchable and tunable band-notched UWB antenna, and the change of the notch band on spectrum fits the prediction 

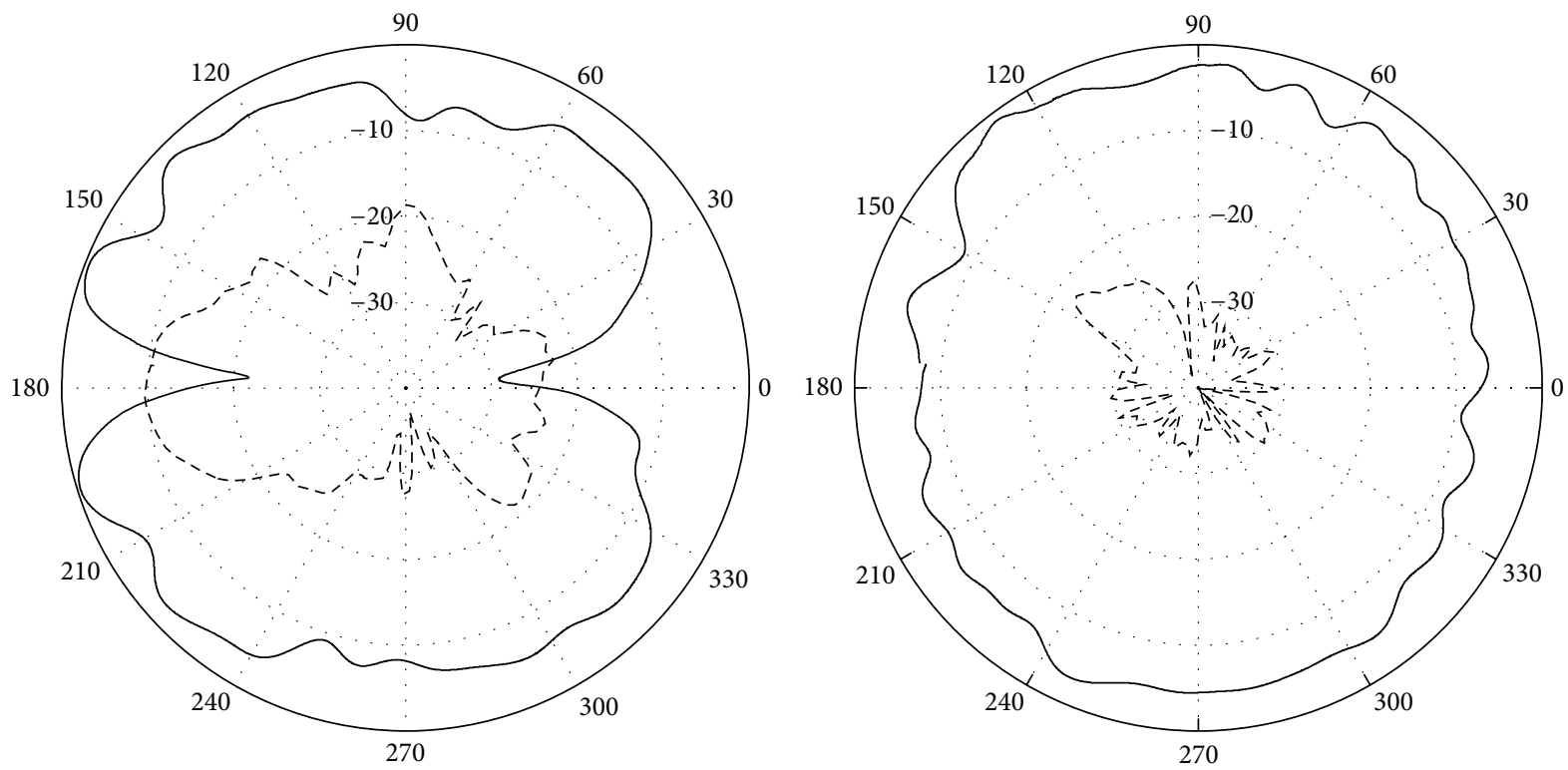

$\begin{array}{ll}\text { - } & \text { Copolarization } \\ --- \text { x-polarization }\end{array}$

$\begin{array}{ll}\text { - } & \text { Copolarization } \\ --- \text { x-polarization }\end{array}$

(a)

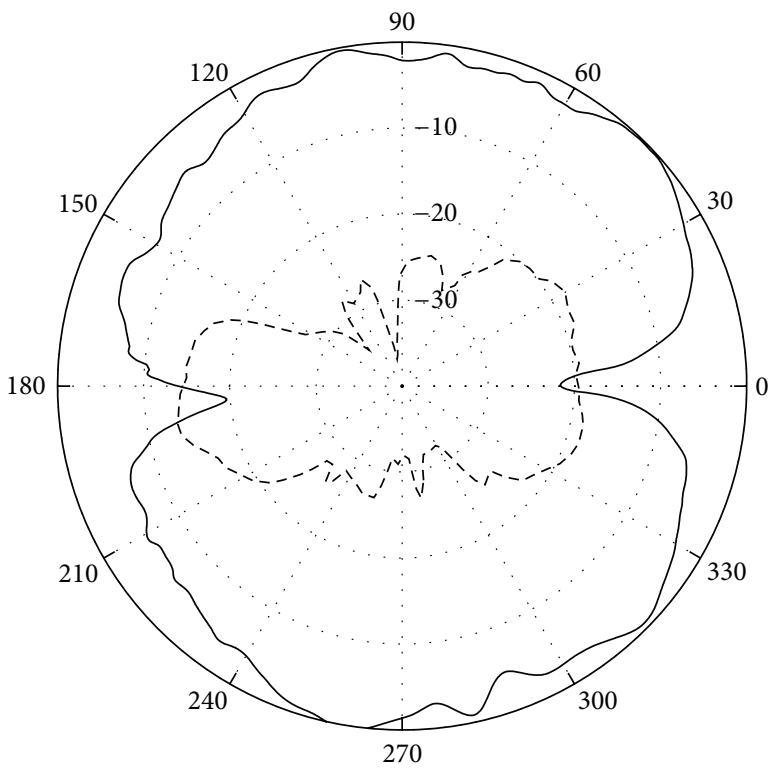

(b)

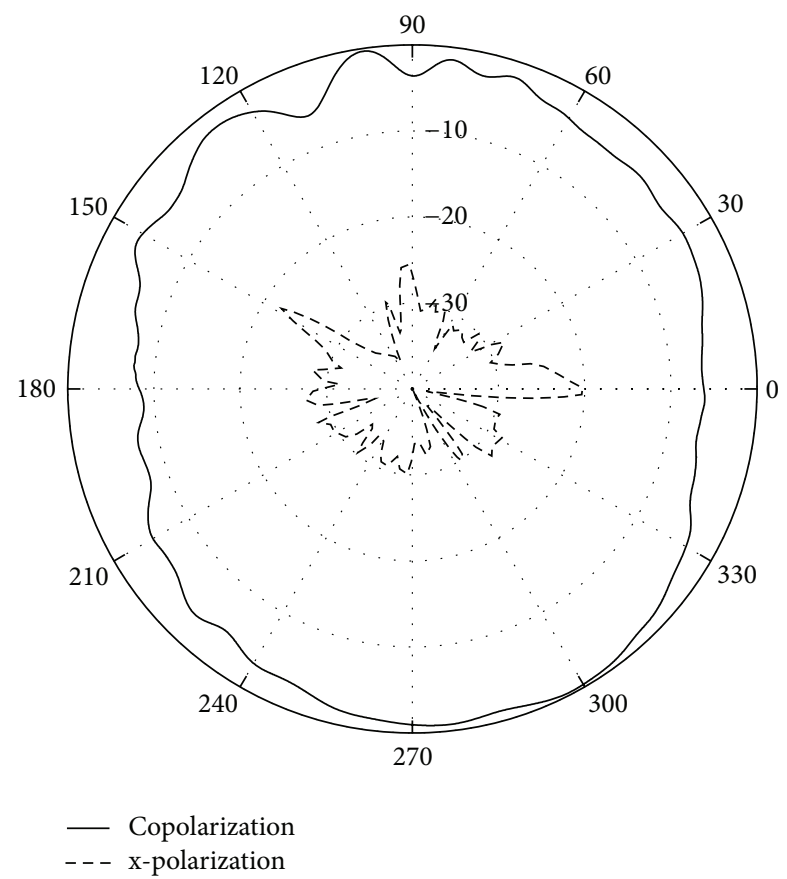

(c)

(d)

FIGURE 7: Measured normalized radiation patterns in $Y O Z$ plane and $X O Z$ plane at two different frequencies: (a) YOZ plane at $4 \mathrm{GHz}$; (b) $\mathrm{XOZ}$ plane at $4 \mathrm{GHz}$; (c) $Y O Z$ plane at $8 \mathrm{GHz}$; (d) $\mathrm{XOZ}$ plane at $8 \mathrm{GHz}$.

of the equivalent circuit very well. That is to say, the PIN diodes work as a switch to choose the lower or upper notch frequency, and varactors produce the tunable performance. It should be noted that using the low loss varactors would improve the notch band performance. The normalized radiation patterns at $4 \mathrm{GHz}$ and $8 \mathrm{GHz}$ when the PIN diodes are
$\mathrm{OFF}$ and the bias voltage on varactors is $0 \mathrm{~V}$ are shown in Figure 7, which look like patterns of the monopole antenna: with 8 -shape in $y$ - $z$ plane and omnidirectional performance in $x-z$ plane. It is clear that the band-notched structure does not affect the omnidirectional radiation behaviour of UWB antenna in $x$ - $z$ plane (H-plane). 


\section{Conclusion}

A novel UWB antenna with switchable and tunable notch bands has been presented. The ON and OFF states of PIN diodes can control the switch between lower and upper notch bands, while the reverse bias voltage on varactors can realize the tunable behaviours. Under the tendency of smart antennas and wearable devices, after combining with adaptive algorithm behind, the reconfigurable band-notched UWB antenna will fit more complicated circumstances.

\section{Competing Interests}

The authors declare that they have no competing interests.

\section{Authors' Contributions}

Wei Wu and Yun-Bo Li contributed equally to this work.

\section{Acknowledgments}

This work was supported by the National Science Foundation of China (61571117, 61501112, 61501117, and 61522106) and the Scientific Research Foundation of Graduate School of Southeast University (YBJJ1435).

\section{References}

[1] J. H. Wang, Y. Z. Yin, and X. L. Liu, "Triple band-notched ultra-wideband antenna using a pair of novel symmetrical resonators," IET Microwaves, Antennas and Propagation, vol. 8, no. 14, pp. 1154-1160, 2014.

[2] T. Li, H. Q. Zhai, L. Li, C. H. Liang, and Y. F. Han, "Compact UWB antenna with tunable band-notched characteristic based on microstrip open-loop resonator," IEEE Antennas and Wireless Propagation Letters, vol. 11, pp. 1584-1587, 2012.

[3] A. Valizade, C. Ghobadi, J. Nourinia, and M. Ojaroudi, "A novel design of reconfigurable slot antenna with switchable band notch and multiresonance functions for UWB applications," IEEE Antennas and Wireless Propagation Letters, vol. 11, pp. 1166-1169, 2012.

[4] S. A. Aghdam, "A Novel UWB monopole antenna with tunable notched behavior using varactor diode," IEEE Antennas and Wireless Propagation Letters, vol. 13, pp. 1243-1246, 2014.

[5] Z. H. Hu, P. S. Hall, J. R. Kelly, and P. Gardner, "UWB pyramidal monopole antenna with wide tunable band-notched behaviour," Electronics Letters, vol. 46, no. 24, pp. 1588-1590, 2010.

[6] Z.-H. Tu, W.-A. Li, and Q.-X. Chu, "Single-layer differential CPW-fed notch-band tapered-slot UWB antenna," IEEE Antennas and Wireless Propagation Letters, vol. 13, pp. 1296-1299, 2014.

[7] B. Badamchi, J. Nourinia, C. Ghobadi, and A. V. Shahmirzadi, "Design of compact reconfigurable ultra-wideband slot antenna with switchable single/dual band notch functions," IET Microwaves, Antennas and Propagation, vol. 8, no. 8, pp. 541-548, 2014.

[8] N. Wang and P. Gao, "A novel printed UWB and Bluetooth antenna with quad band-notched characteristics," in Proceedings of the International Workshop on Microwave and Millimeter
Wave Circuits and System Technology (MMWCST '13), pp. 150153, Chengdu, China, October 2013.

[9] Y. F. Weng, S. W. Cheung, and T. I. Yuk, “Triple band-notched UWB antenna using meandered ground stubs," in Proceedings of the 6th Loughborough Antennas and Propagation Conference (LAPC '10), vol. 10, pp. 341-344, IEEE, Loughborough, UK, November 2010.

[10] J. Wang, Y. Yin, T. Wang, and X. Liu, "Compact dual-bandnotched UWB antenna with high notch-band-edge selectivity," Microwave and Optical Technology Letters, vol. 55, no. 10, pp. 2507-2513, 2013.

[11] A. Foudazi, H. R. Hassani, and S. M. A. Nezhad, "Small UWB planar monopole antenna with added GPS/GSM/WLAN bands," IEEE Transactions on Antennas and Propagation, vol. 60, no. 6, pp. 2987-2992, 2012.

[12] J. Xu, D. Shen, X. Zhang, and K. Wu, "A compact disc ultrawideband (UWB) antenna with quintuple band rejections," IEEE Antennas and Wireless Propagation Letters, vol. 11, pp. 1517-1520, 2012.

[13] N. Tasouji, J. Nourinia, C. Ghobadi, and F. Tofigh, "A novel printed UWB slot antenna with reconfigurable band-notch characteristics," IEEE Antennas and Wireless Propagation Letters, vol. 12, pp. 922-925, 2013.

[14] A. A. Kalteh, G. R. DadashZadeh, M. Naser-Moghadasi, and B. S. Virdee, "Ultra-wideband circular slot antenna with reconfigurable notch band function," IET Microwaves, Antennas and Propagation, vol. 6, no. 1, pp. 108-112, 2012.

[15] L. Kurra, M. P. Abegaonkar, A. Basu, and S. K. Koul, "Switchable and tunable notch in ultra-wideband filter using electromagnetic bandgap structure," IEEE Microwave and Wireless Components Letters, vol. 24, no. 12, pp. 839-841, 2014.

[16] E. Antonino-Daviu, M. Cabedo-Fabrés, M. Ferrando-Bataller, and A. Vila-Jimenez, "Active UWB antenna with tunable bandnotched behaviour," Electronics Letters, vol. 43, no. 18, pp. 959960, 2007. 


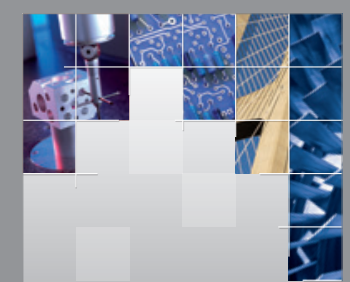

\section{Enfincering}
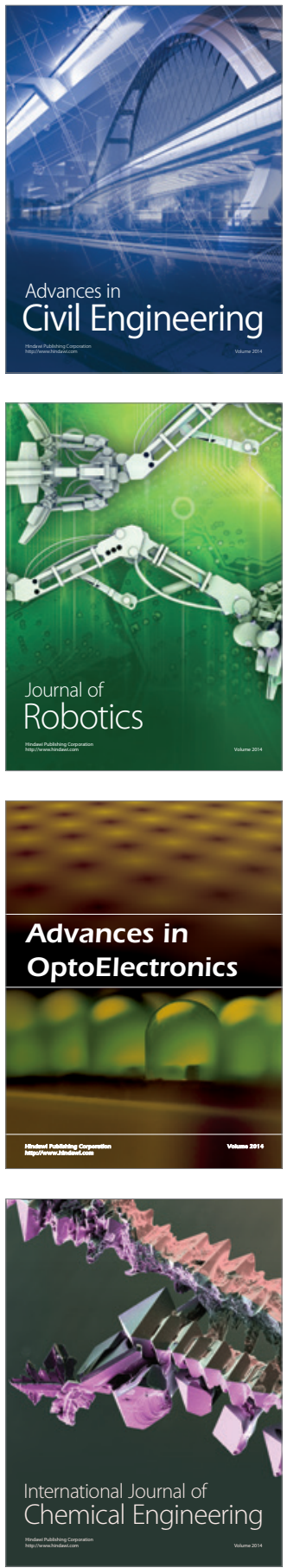

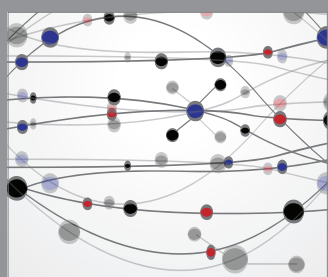

The Scientific World Journal

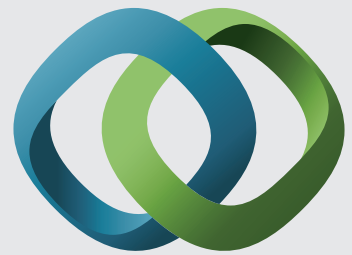

\section{Hindawi}

Submit your manuscripts at

http://www.hindawi.com
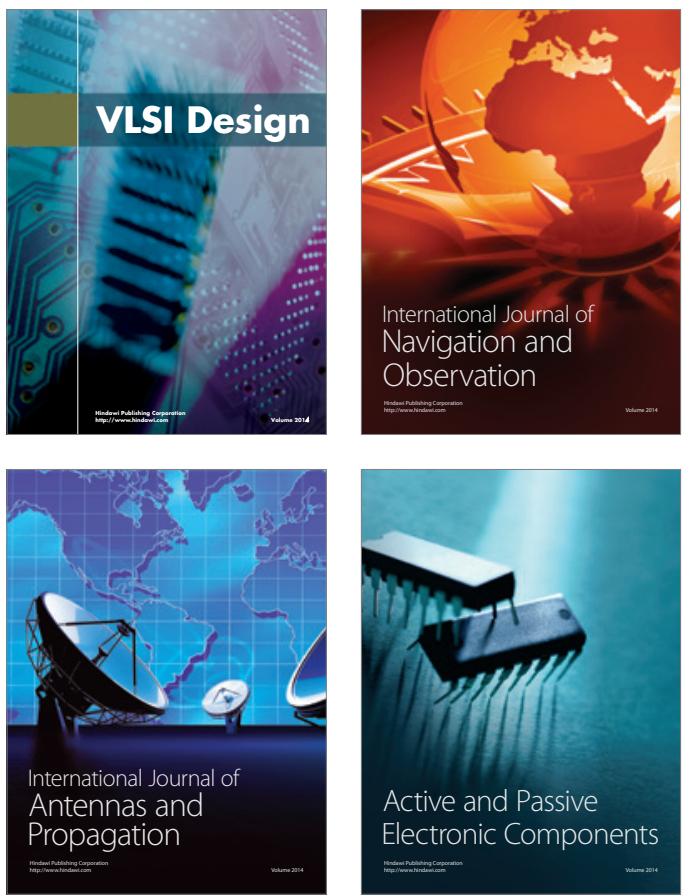
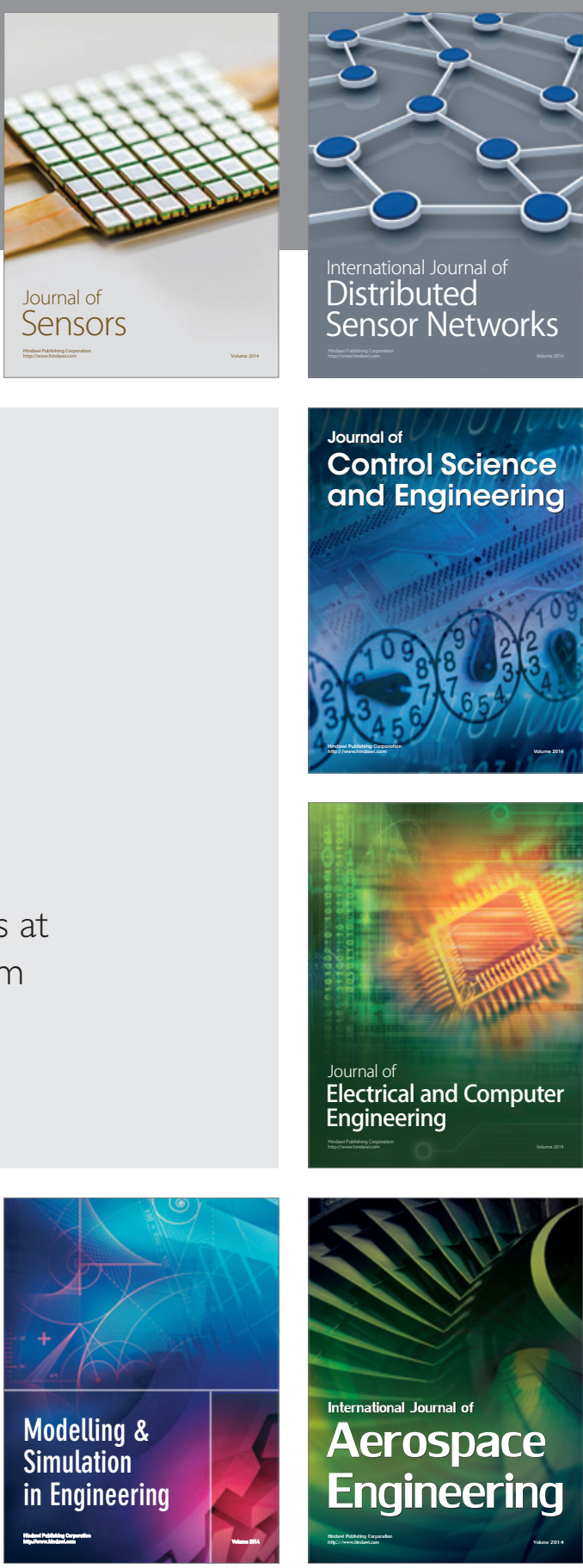

International Journal of

Distributed

Sensor Networks

Journal of

Control Science

and Engineering
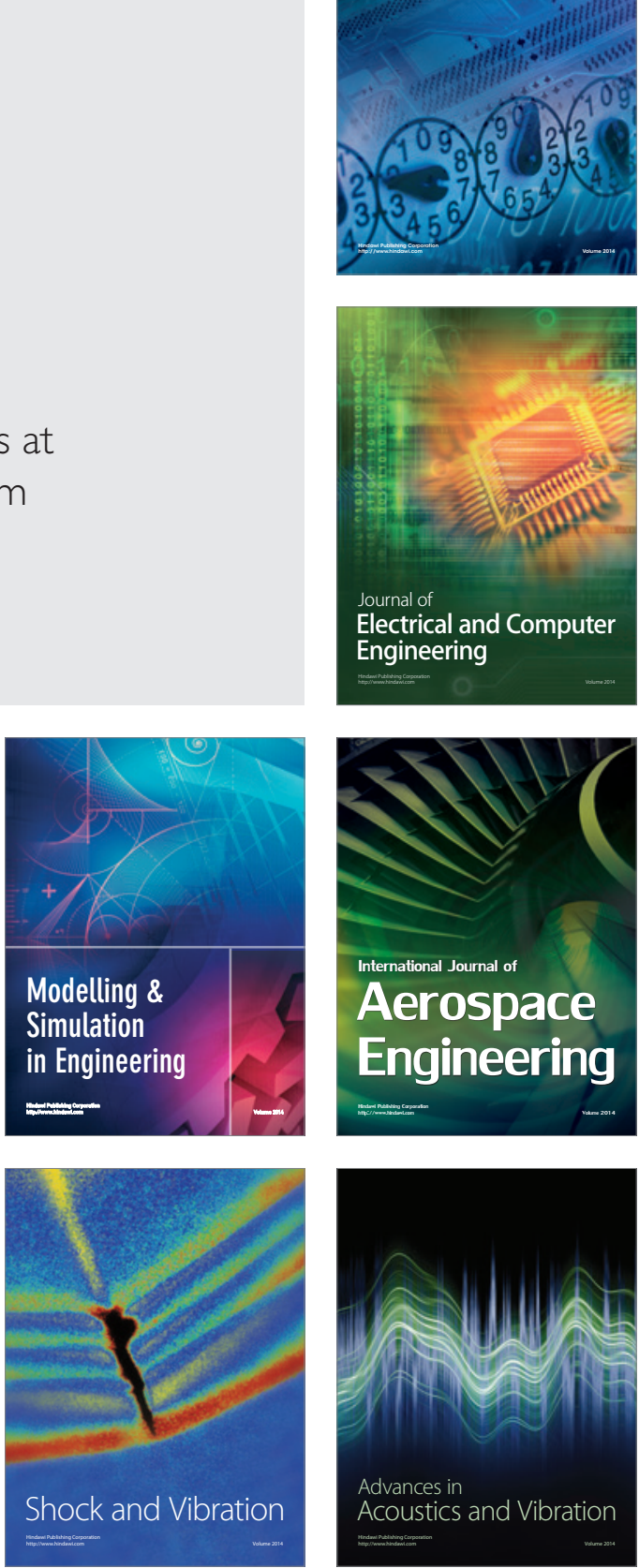